\section{As práticas corporais/atividade física nos 30 anos do Sistema Único de Saúde}

Body practices/physical activity

in the 30 years of the Unified Health System

Mathias Roberto Loch ${ }^{1}$

Alan Goularte Knuth ${ }^{2}$

Inácio Crochemore Mohnsam Silva ${ }^{3}$

Paulo Henrique Guerra ${ }^{4}$

${ }^{1}$ Programa de Pós Graduação em Saúde Coletiva, Universidade Estadual de Londrina. Londrina $P R$ Brasil.

${ }^{2}$ Instituto de Educação, Universidade Federal do Rio Grande. Rio Grande RS Brasil.

${ }^{3}$ Universidade Federal de Pelotas. Pelotas RS Brasil.

${ }^{4}$ Universidade Federal da Fronteira Sul. Chapecó SC Brasil.

Primeiramente parabenizamos a Revista Ciência \& Saúde Coletiva (CSC) pela formidável edição "30 anos dos Sistema Único de Saúde (SUS)". Dito isso e entendendo que seria impossível a organização de uma edição que contemplasse todos os temas pertinentes ao SUS, destacamos a ausência de um artigo que abordasse de maneira mais específica a promoção das práticas corporais/atividade física (PCAF), ainda que um dos artigos cite a questão no contexto da Política Nacional de Promoção da Saúde ${ }^{1}$.

Ressaltamos que o Brasil é pioneiro na introdução das PCAF nas políticas públicas de saúde². Em 2013, uma alteração na lei 8.080, incluiu a atividade física como fator determinante e condicionante da saúde $e^{3}$ além de terem acontecido, nos últimos anos, importantes avanços na produção do conhecimento e da Vigilância relativos

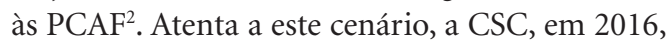
dedicou uma edição específica ao tema ${ }^{4}$.

É bem verdade que o núcleo profissional da Educação Física, principal, mas não único, "responsável" pela promoção das PCAF, ainda tem muito a avançar para se consolidar no SUS. Recente artigo, nesta mesma CSC, analisou distanciamentos e interfaces entre os campos da Educação Física e da Saúde Coletiva, refletindo sobre a importância do olhar para o campo social na temática ${ }^{5}$.

Não temos dúvida que a pauta das PCAF, enquanto questão de saúde pública no Brasil, avançou muito desde a criação do SUS e que as PCAF podem desempenhar um papel importante no enfrentamento da complexa situação de saúde brasileira. Mas sem ingenuidades e simplismos, visto que o papel protetor ou de tratamento das PCAF pode, inclusive, fortalecer o olhar biomédico em detrimento ao princípio da integralidade. Aliás, consideramos que o tema das PCAF tem grande potência no sentido de ser um dos que mais efetivamente pode se "desvencilhar" do olhar centrado no adoecimento, tão marcante na área da saúde.

Reconhecendo-se a multiplicidade e a amplitude dos fatores associados às PCAF, acreditamos que o seu acesso deve ser encarado como um direito humano básico e não como um privilégio, restrito aos indivíduos que por tais "serviços" possam pagar. Ao mesmo tempo é preciso fugir de uma abordagem que considera a prática de PCAF como "obrigação", com o consequente "julgamento" das pessoas que não aderem a alguma prática. Nesse sentido, acreditamos que o SUS tenha um papel importante no aumento do acesso à sua prática, coerente com o princípio da equidade, podendo ter também um relevante papel de articulação entre diferentes setores, já que não cabe somente ao setor saúde a promoção das PCAF. Do mesmo modo, é preciso que os serviços de saúde não entendam as PCAF como algo isolado das demais estratégias e ações.

Uma considerável parcela dos avanços que a promoção das PCAF teve no Brasil nas últimas décadas se deu em função do SUS. Entretanto, reconhecemos que ainda há um longo caminho pela frente para a consolidação desta pauta no SUS. Os desafios são complexos e vão desde a melhoria da formação profissional até a garantia de que existam recursos para o investimento em promoção das PCAF.

\section{Referências}

1. Malta DC, Reis AAC, Jaime PC, Moraes Neto OL, Silva MMA, Akernan M. O SUS e a Política Nacional de Promoção da Saúde: perspectiva resultados, avanços e desafios em tempos de crise. Cien Saude Colet 2018; 23(6):1799-1809.

2. Hallal PC. Atividade física e saúde no Brasil: pesquisa, vigilância e políticas. Cad Saude Publica 2014; 30(12):2487-2489.

3. Brasil. Lei $n^{\circ} 12.864$, de 24 de setembro de 2013. Altera o caput do art. $3^{\circ}$ da Lei $n^{\circ} 8.080$, de 19 de setembro de 1990, incluindo a atividade física como fator determinante e condicionante da saúde. Diário Oficinal da União 2013; 24 set.

4. Gomes R, Minayo MCS. Atividade física como parte importante da saúde em todas as idades. Cien Saude Colet 2016; 21(4):998-998.

5. Nogueira JAD, Bosi MLM. Saúde Coletiva e Educação Física: distanciamentos e interfaces. Cien Saude Colet 2017; 22(6):1913-1922. 
